\title{
Alicias ante el espejo. Trabajadoras sociales en busca de la participación. Chile en los sesenta ${ }^{1}$
}

\author{
M. Angélica Illanes $0 .^{2}$
}

\section{SÍNTESIS}

El texto sigue la génesis y evolución del concepto de "participación" en los años sesenta, puesta en las manos y tal como es recogida por el discurso y la práctica de algunas asistentes sociales, bajo la inspiración de las fuentes teóricas -teológicas, sociológicas, políticas y pedagógicas-que circularon en Chile y América Latina en los sesenta. Esta opción metodológica para estudiar la teoría, nos permite visualizar el impacto que ésta tiene en la formación y el quehacer de personas y actores concretos de la sociedad. En específico interesa el modo de apropiación y reelaboración en Latinoamérica tal como lo vivieron ciertas mujeres trabajadoras sociales concretas en el seno de sus escuelas y de la sociedad en que se insertan.

\begin{abstract}
The present article narrates the genesis and evolutions of the concept "participation" during the sixties, just like it was gathered by the speech and the practice of some women social workers, under the inspiration of theorical sources -theological, sociological, politic and pedagogic sources- that were in traffic in Chile and Latin America in the sixties. This methodological option allows us to look into the impact that this theory has in the formation and the occupation of concretes actors of our society, to knowing, the women social workers.
\end{abstract}

Palabras clave: Servicio social - Participación popular - años sesenta mujeres trabajadoras sociales.

Key words: Social work - Popular participation - The sixties - Women social workers.

\section{Preámbulo}

\section{Hubo una vez este país: ausencia y memoria de la "participación" en Chile}

Hubo una vez este país en que los habitantes de todos los estratos, especialmente los populares, se movilizaban y congregaban. 
Fue el afamado tiempo de la participación popular, cuando desde todos los flancos civiles, como también gubernamentales y eclesiales, se empujaba en ese camino. Dicha participación pasó, así, a constituir uno de los problemas centrales de la política, en tanto que en ella se pondría a prueba la factibilidad histórica de una posible "democracia real." Ante aquel espectáculo de vida histórica, lo que actualmente vivimos en términos participativos se parece a un territorio devastado, silencioso, solitario, señal del paso de la guerra, de la muerte o la despoblación. Para muchos este paisaje parece tener, al fin, orden: el bien más apreciado por los regímenes y gobiernos de todos los signos y colores ideológicos... No obstante, por muy interesado que esté un determinado régimen político en el "orden," ello no quita que se preocupe por la cuestión de la "participación social," porque cuando ella está ausente, atraviesa silenciosa los pasillos y salones de palacio una sombra oscura: un temor de congelamiento, de parálisis, instalándose una tremenda soledad gubernativa.

Por ello el discurso de campaña de la actual gobernante chilena, Michelle Bachelet, estuvo centrado en la democratización participativa; se percibían los indicios de la agonía de la "ciudadanidad," de cuya vida y pertenencia depende la salud y fortaleza de cualquier sistema que aspire a ser "democrático." No obstante, se sigue gobernando sobre la base de "mesas de diálogo," con escasa representación de la ciudadanía demandante de cambios y participación real. ${ }^{3}$ Así, a pesar de los positivos índices macroeconómicos chilenos, el malestar cunde, una sensación de opresión, de impotencia e incluso de falta de libertad, se despliega crecientemente entre la ciudadanía. ${ }^{4}$ Los jóvenes sienten y viven, bastante angustiosamente, la tensión entre su deseo de constituirse en "sujetos históricos" a través de la participación activa en la construcción de su sociedad, y la falta de canales y organizaciones con credibilidad, a través de las cuales realizar su vocación participativa. “QQué podemos hacer para cambiar este sistema?," es una pregunta habitual que plantean los/as jóvenes, intentando buscar respuestas desde el "saber académico."

Habrá entonces que indagar en los documentos y las páginas de la historia. Recoger la experiencia de otros tiempos y de generaciones pasadas para ver qué se entendió por aquello de la 
"participación," para saber bajo qué condicionantes históricos se pudo dar, para conocer sus soportes teóricos e ideológicos y los proyectos políticos que le sustentaban y su relación con los "saberes." Tarea que nos sobrepasa en este breve texto, pero que nos inspira, ya que, como decimos, en torno a la cuestión de la participación está siempre en juego el problema de la "democracia."

\section{Introducción}

\section{La ideología participativa}

En los 60, la participación se proponía como un imperativo ético. La 'sociedad justa' (...) no era sólo aquella en la que los beneficios se distribuían en forma más equitativa, sino, básicamente, una convivencia en la que todos habrían de compartir responsabilidades, tareas y decisiones. En ese momento, quienes no queríamos ser liberales entendíamos que la naturaleza humana era, básicamente, igualitaria y que las diferencias socioeconómicas (que no son lo mismo que las variaciones entre los individuos) expresaban más las relaciones según las cuales, históricamente, se ordenaba (o desordenaba) cada sociedad. ${ }^{6}$

El horizonte de nuestra investigación se pregunta por qué y con qué fundamentos en los años sesenta y primeros tres años de la década del setenta del siglo XX se planteó la necesidad, por parte de todos los sectores, civiles e institucionales, de transformar la democracia liberal en otra: social. Al parecer se vivía, ya en los años sesenta, un "punto de saturación" de dicha democracia liberal: límite o saturación que algunos diagnosticaron como "crisis integral" o como punto final del sistema capitalista. Entonces se planteó la necesidad de transformar la sociedad a través de la superación de la democracia liberal burguesa y la construcción de "otra-democracia," sustentada principalmente en la participación social y popular. ¿Qué se quería decir con "participación"?

Mientras el gobierno de la Democracia Cristiana (D.C.) nombró a su política de participación, "promoción popular," poniendo el acento en las motivaciones "integracionistas" de su política social y de su proyecto, el gobierno de la Unidad Popular (U.P.) 
habló de "poder popular," enfatizando el carácter "revolucionario" de su política social y de su proyecto político. En términos políticos generales, pensamos que, a pesar de sus diferencias, ambos gobiernos buscaron, por la vía de la activa participación popular en general y de una política social participativa, en particular, construir una nueva democracia ("comunitaria o de socialización" uno, "socialista" el otro) como una utopía política de nuevo cuño y como un experimento político moderno propiamente latinoamericano en el otoño del siglo XX.

En este texto nos instalamos en el campo histórico específico de los sesenta, indagando brevemente en algunos aspectos del ideario de la participación popular, especialmente en el sentido de su impacto en los saberes y las prácticas. Al respecto, nos preguntamos: ¿cuál es la relación que se establece, en un determinado momento histórico, entre ideología, saber y acción profesional?

En general, en el orden político, la participación social-popular se gatilló en los sesenta a partir de la propia efervescencia de una sociedad en estado de vida y conciencia crítica. Siguiéndole los pasos, ella fue acompañada por la formulación de lo que identificamos como una "ideología participativa" proveniente, especialmente, de una nueva teología que, ya desde un lenguaje religioso-sociológico europeo-vaticano (Vekemanns, Mattelart y diversas voces eclesiales), así como desde la Teología y Pedagogía de la Liberación latinoamericana (Freire), buscaba aterrizar en la historia y la política de los sesenta. La metafísica teológica buscaba el mundo de la experiencia; la ideología y la religión intentaban superar la acusación del positivismo, de su "ruptura histórica entre el lenguaje y lo expresado;"7 era un tiempo para la búsqueda de la "autenticidad" y su expresión en una voluntad política. Considerada como narrativa de una época, la ideología-participativa exprimía el zumo de ciertos principios éticos con implicaciones radicales, ${ }^{8}$ que tendía a movilizar pasiones y acciones. No obstante, esta narrativa estaba, al mismo tiempo, produciendo un "discurso de poder" como insumo a partir del cual instaurar nuevos regímenes políticos en América Latina que, a través de la participación como "discurso de verdad," fundasen un nuevo orden institucional legitimador del 
pueblo como cuerpo activo en cierto nivel de la toma de decisiones, ${ }^{9}$ encauzando los síntomas de su deseo de poder.

Así, la "participación" habría sido favorecida y estimulada, simultáneamente, por una serie de "agentes externos" al movimiento popular: teólogos, estatales, profesionales y civiles, los que, apoyados en lo que identificamos como una "ideología participativa," impulsaron una acción política de "inducción participativa" en el seno del pueblo. Esta "ideología e inducción participativa," impulsada por arriba, por afuera y por el lado del movimiento popular, no sólo habría delineado una nueva forma de concebir la política social, sino más aún, un nuevo orden fundado sobre una renovada concepción del pacto social, en vista de la transformación del propio régimen político y del carácter de la democracia y de la sociedad en el Chile de los sesenta.

Es decir, se habría actuado desde el planteamiento de que el propio orden sociopolítico en Chile podría y debía transformarse desde y a partir de la base popular organizada y participativa; participación que era la piedra basal sobre la que se podría construir conciencia social, pertenencia nacional y ciudadanía política, es decir, "democracia," concebida como "toma-social de decisiones." Este planteamiento, de importante trascendencia política, significaba una opción por la superación de la "democracia liberal" y por la construcción de una democracia social definida como "socialización." La opción política consistió en promover la participación popular desde arriba, aumentando la corriente de las aguas que organizaban y movilizaban desde la base. Como resultado, pensamos que la política de participación social, más allá de haber generado una "revolución de expectativas," como comúnmente se ha planteado, contribuyó al desarrollo en Chile de un proceso de democratización ampliada que sentó las bases para un nuevo régimen político democrático chileno-latinoamericano definido como "socialización," generando, al mismo tiempo, un proceso de concientización que se subió al carro de la utopía política del continente, contribuyendo a trazar el camino político de la hora. ${ }^{10}$

Lo que aquí nos interesa remarcar es que esta "ideología participativa" habría adquirido la dimensión de un verdadero paradigma, 
llegando a crear nuevas disciplinas y transformar saberes en vista de la construcción de una nueva sociedad. De inmediato uno habría esperado que la D.C. en el gobierno, buscara a la escuela de Servicio Social de la Pontificia Universidad Católica (P.U.C.) para la puesta en práctica de este paradigma participativo en los sesenta. Algo así había ocurrido varias décadas antes: al momento de levantarse el modelo de Estado Asistencial y Legislador el año 1925 en Chile, se fundó el aparato cultural ad hoc que pusiese en carne y sangre dicho proyecto político: la Escuela de Servicio Social, sin la cual aquel era una mera abstracción. Así, cabe entonces preguntarse ¿cómo se relaciona en los sesenta la "ideología participativa" con el saber y la práctica del Servicio Social que, desde el año 1925, estaba interviniendo directamente sobre el mundo de la sociedad civil y popular?... Al parecer, esta vez el Servicio Social no fue considerado como el saber y la disciplina más adecuada para la implementación de la política e ideología participativa. Posiblemente se le vio -tal como a menudo se le criticaba- como un saber disciplinario comprometido históricamente con el ordenamiento tradicional imperante. La "ideología participativa" creará, pues, una serie de instituciones ad hoc para la difusión de dicho paradigma ("Consejería Nacional de Promoción Popular," entre otras), e incluso fundará una nueva disciplina profesional en la propia P. Universidad Católica: la Escuela de Sociología, llamada a servir de cuna formadora de vanguardias intelectuales (¿bien "masculinas"?) en vista de este paradigma democrático-social.

Observando históricamente la relación entre ideología y saberes, percibimos que la ideología, con la chispa de su zumo ético, es fuego que prende aquellos saberes que están a favor de su poder o su viento, tendiendo a enfriar aquellos que buscan su resguardo en el muro del miedo. Enfriamiento de estos saberes "antiguos" que es, al mismo tiempo, el momento de su crítica y del desprendimiento sigiloso de sus Alicias, quienes, osando mirarse en el espejo de sí mismas, huyen de la muerte, avanzando pioneras en pos de la transformación, en busca de la lumbre. Fue así que las Alicias, sigilosamente, desde el Trabajo Social, "robaron" el fuego de la ideología participativa y buscaron introducirse en el país de las maravillas, al paso que la antigua institución disciplinar enmudecía y se caía a pedazos... Uno de los 
rostros de este texto es mostrar algo acerca de cómo las ideologías "juegan" con lo históricamente existente, apagando, prendiendo, atrayendo y transformando los saberes y las prácticas. Y quizás podríamos decir que, históricamente, lo que muere, se prende por otro lado: por el lado donde la idea se narra en verbo amor, se embarra con la pala y la picota y camina a vuelo alzado con el globo de color.

Este texto tiene como objetivo principal referirse a algunas de las ideas de la "ideología participativa" de los sesenta puesta en manos de algunas Alicias. Aquí planteamos que ellas, premunidas y prendidas de esta nueva ideología, deciden salir, casi solas, en busca del país de las maravillas, especialmente en busca de sus mujeres, calentándose al fuego de un nuevo diálogo. Ellas buscan a sus mujeres como las llamadas a propiciar la nueva participación y las buscan como las más necesitadas de esa democracia participativa. A los ojos de las Alicias, "la democracia" y "la participación" tenían rostro femenino.

Debo advertir que esta es una historia a "pequeña" escala; una historia a la que le interesa visualizar las "grandes" ideas puestas en manos pequeñas y en cuerpos singulares, con nombre propio, solitarios; ideas en manos de una que otra vagamunda de ojos abiertos. Interesa contar aquí la historia de algunos de esos pequeños-tremendos esfuerzos que elevan globos de colores en una sola mano. Algunos dicen que la tela de la historia se teje de ese modo: con la porfía de algunos pocos que deciden invitar a hacer... Puede ser. Pero, en realidad, ellas no elevaban globos locos o solitarios; transitaban por un camino ya abierto por una ideología que se había abandonado a la historia y por un proyecto político que había tomado la pala de construcción de la vía pública. Pero estas Alicias insistían en levantar su propio globo de color, apropiándose de los lenguajes para darles su genuina concreción histórica, haciendo de esa lengua ideológica un saberpoder de ellas. Pues ellas se consideraban las que mejor sabían del lugar preciso donde las palabras podrían encontrarse con la vida, es decir, con las mujeres (profesionales y populares) de los sesenta. 


\section{Alicia ante el espejo de la mañana}

En el Chile de los sesenta, los cambios se cocinaron primero en el caldero de los volcanes sumergidos en el mar del sur del mundo. El terremoto ocurrió en mayo de 1960. Todas las discusiones suspendieron momentáneamente sus habladurías, acalladas ante el espectáculo terráqueo, dejando el paso al lenguaje de los ritos. El pueblo mapuche entregó al mar su niño, mientras en las calles de las ciudades se recogía en largas bolsas de géneros la colecta para los damnificados y en las parroquias se rezaba y clasificaban las rumas de ropa. Los niños sureños, rescatados del miedo a las desatadas fuerzas de la naturaleza, llegaban al norte en barcos de la marina nacional y eran ubicados en hogares de Valparaíso, La Serena y la capital. El país tuvo la oportunidad de mirarse a sí mismo de norte a sur, recogiéndose en un abrazo. Se decía que la solidaridad brotaba en Chile con los terremotos.

El Servicio Social de los años 60 se estremece ante el espectáculo. Las jóvenes estudiantes del norte se llenaron de sur: partieron a solidarizar, encuestar, entregar, acompañar, reconstruir. El servicio social oficial se organizó sobre la base de Jefas de Plaza en las zonas devastadas, encargadas de coordinar el trabajo de las asistentas profesionales, articuladas con las damas de las localidades. A la zona de Valdivia, una de las áreas más dañadas, llegaron las asistentes sociales, las que, unidas a las damas del Círculo de Valdivia, embarcaron cientos de niños sureños al norte; sus padres no temieron confiárselos: querían salvarlos del amenazante rebase de las aguas del lago Riñigüe.

Las emergencias nacionales son, sin duda, momentos especiales en la vida de los pueblos, cuando las heridas de la tierra y de las almas ponen entre paréntesis las críticas teóricoideológicas, tales como las que por esos años se comenzaban a plantear en la política y los movimientos sociales latinoamericanos, cuyas voces críticas hacían eco y retumbaban fuerte en las paredes del Servicio Social latinoamericano, cuestionado y culpado de constituir un saber y una práctica obstaculizadora de los cambios. ${ }^{11}$ 
No obstante, el terremoto del sesenta no es capaz de explicar el silencio casi total que mantiene, respecto del movimiento latinoamericano de "reformulación del Servicio Social," la revista chilena Servicio Social, órgano de la Escuela de Servicio Social de la Beneficencia y de este saber disciplinar en Chile durante casi cuarenta años. Este silencio se puede explicar como defensa ante una crítica que sin duda estaba poniendo en jaque las bases y fundamentos mismos del Servicio Social como saber y como práctica en América Latina, respecto del cual la Escuela de Servicio Social de la Beneficencia chilena se consideraba escuela matriz en Latinoamérica. Pero llama la atención un segundo silencio de dicha revista en los sesenta: su enmudecimiento respecto del programa de la nueva política social de Promoción Popular que estaba poniendo en práctica el gobierno D.C. desde 1964 y que sin duda estaba, desde ya, afectando las prácticas de intervención en los sectores poblacionales y campesinos en Chile. Silencio este último quizás explicable como una actitud de riguroso celo por la "autonomía" del saber disciplinar -algo bastante inédito en el Servicio Social- respecto de un proyecto político específico que llegaba al gobierno en el país. Doble silencio que fue ahogando a dicho órgano de expresión en aquel bravo oleaje crítico de los sesenta en el que no supo o no quiso nadar. La agonía del principal órgano de expresión del Servicio Social chileno se prolongó a lo largo de los años sesenta, hasta morir en 1967, en víspera de los movimientos de reforma que despierta el año 1967 y 1968 en las distintas escuelas chilenas de Servicio Social.

Pero si los "silencios oficiales" parecen acallar la historia, afortunadamente ésta -cual río rebelde que busca otros cauces y derroteros para sus aguas dulces deseosas de mar- aflora por otras vías, tímidas, sin cauce conocido, de derrame desordenado y fragmentario, pero evidentes. Lo que hoy día podría ser un tabú, cual es la manifestación explícita de la relación entre paradigma ideológico/político y saber/práctica en el campo de una disciplina profesional, en el caso del servicio social era algo común. Ya mencionamos la relación entre el proyecto político de Estado asistencial y escuela de servicio social en 1925; algo semejante ocurre con la Escuela de Servicio Social de la P. Universidad Católica y el proyecto de las clases conservadoras. Esta escuela, desde su fundación, se había puesto al servicio de los mandatos 
de la Iglesia y de las elites propietarias chilenas (y también del Estado en períodos de emergencia), especialmente en la fase previa al advenimiento del Frente Popular, cuando la escuela fue contratada por la Asociación de Agricultores para efectuar un trabajo institucional en función de la defensa del orden agrario en Chile, el que entonces se sintió amenazado. ${ }^{12}$ Sin embargo, en los sesenta, la Escuela de Servicio Social P.U.C., si bien participó en las Semanas Sociales (una instancia de delineamiento y capacitación en las nuevas políticas de promoción popular de la Iglesia y de la D.C. y que se realizaron en Chile a partir de 1963), esta vez no puso sus cuadros profesionales al servicio del proyecto de promoción popular. Sin embargo, algunas de sus bases estudiantiles de cultura cristiana, comenzaron a circular entre los espacios donde se difundían los nuevos preceptos ideológico políticos de aquel entonces, específicamente los de "promoción popular," los que, por lo demás, estaban anidando muy cerca de dicha Escuela de Servicio Social P.U.C.: en la recién fundada Escuela de Sociología de esa Universidad, donde sus creadores, los sociólogos cristianos belgas, S.J. Roger Veckemans y Armand Mattelart, estaban elaborando y difundiendo su pensamiento, su diagnóstico de la sociedad chilena y su propuesta de tratamiento político.

Una de estas estudiantes que salieron en busca del proyecto político que se formulaba y se comenzaría a implantar en el país fue Alicia. Ella comenzó a asistir a las conferencias que impartía el año 1963 el sacerdote Roger Veckemanns en el Instituto Humanístico, acerca de los fundamentos teóricos y éticos de una "sociedad democrática." Alicia también participó de las Jornadas Sociales donde se difundían los nuevos principios del proyecto de sociedad y estado comunitario. De su asistencia a las conferencias de Veckemanns, Alicia anotó que la persona humana se definía fundamentalmente en su relación con otro, con el que establecía un diálogo, a través del cual el ser humano se desarrollaba como persona, en tanto ser inteligente y con voluntad de amar. Este diálogo con el otro, fundante del propio ser de la persona, era lo que definía el "principio de solidaridad," cimiento de la sociabilidad. "Fuera de la solidaridad, el hombre no puede realizar su naturaleza, su esencia de persona humana y, por lo tanto, una sociedad que no se preocupa de asegurar o de asegurarse a sí misma como tejido propio la solidaridad, será una sociedad 
que necesariamente se va a oponer a lo que el hombre es en lo más íntimo de su ser," anotó Alicia en sus apuntes de la conferencia de Veckemanns. ${ }^{13}$

Una sociedad dentro de la cual se respete el principio de solidaridad, dará cabida a que todos y cada uno de sus miembros resuelva aquello que dice relación con su destino personal, sin que se menoscabe la importancia del nosotros comunitario. Podemos comparar este principio con la sangre que vivifica un organismo, dentro del cual hasta las células más pequeñas cumplen con su función específica, función que guarda una íntima relación de dependencia con el resto de las partes integrantes del todo. $^{14}$

Así, desde la propia esencia de la "persona" se fundamentaba el principio de "comunidad" y sociedad como un todo orgánico vitalmente articulado entre sus partes constitutivas. Respecto del rol del Estado en este modelo de sociedad, Alicia toma nota del principio de "subsidiariedad" que, según Veckemanns, definiría el rol del Estado como una acción tendiente a la "unificación (de la sociedad) en vista a una meta o fin común," ya que esta unidad, a causa de la imperfección humana, no se lograría espontáneamente. De ahí el rol del Estado, el que a través del "subsidio" o el "auxilio," estimularía a las bases para asumir por sí mismas la responsabilidad de su propio bien común. Lo cual no significaría -dijo el sacerdote jesuita a través de las anotaciones de Alicia- que la autoridad pueda desaparecer ya que la imperfección humana, en la que dicha autoridad tendría su origen, "no podrá superarla nunca el hombre en su condición temporal." ${ }^{15}$

Esta misión histórica y tarea de subsidiariedad del Estado la llevaría a cabo -a juicio de Carlos Domínguez, expositor de las Jornadas Sociales realizadas en Osorno en 1964, a las cuales asistió Alicia- a través de cinco funciones: coordinación, orientación, estímulo, organización e integración. Lo cual, en suma significaba: que el Estado pusiese a disposición de las bases todos los recursos y esfuerzos posibles para estimular su acción y organización (pudiendo suplirla transitoriamente en caso que dichas bases sociales no respondieran a dichos estímulos), debiendo asumir el Estado la responsabilidad de su integración en un "cuerpo 
orgánico bien estructurado que permita lograr el Bien Común General." ${ }^{16}$ En este concepto y función del Estado como armonizador de la sociedad y constructor y encarnación del Todo, es fácil reconocer la teoría filosófica del Estado de Hegel; un Estado definido como el lugar histórico del Absoluto, del Todo y de la Verdad como Conciencia de Sí; punto final sintético de toda contradicción histórica: es decir, el lugar de la Utopía.

Ante este sueño de país que despertaba a la aurora de su solidaridad y comunidad como proyecto político, Alicia no podía permanecer indiferente. Necesitaba repensar y posicionar su saber y su disciplina en dirección de la utopía social que advenía. Decidió, así, hacer su memoria de título en el estudio de "Algunos aspectos de la realidad actual en relación al Servicio Social," presentado el año 1964 a la Escuela de Servicio Social 'Elvira Matte de Cruchaga' de la P. Universidad Católica de Chile, para optar al título de Asistente Social. A pesar de que dicha memoria no obtuvo más que una nota 5.0, un miembro de la comisión evaluadora reconoció "la novedad y actualidad del tema, la inquietud y altura de miras que revela (la autora) al abordar un estudio de esta naturaleza, (tratando) los principios básicos de la Promoción Popular al nivel de los estudios realizados en el país y al acceso de un estudiante universitario. ${ }^{17}$ En efecto, a través de este trabajo, Alicia Montes asimila todos los conceptos que en ese momento están fundamentando en Chile la participación social como doctrina político-social de la Iglesia Católica metropolitana para Latinoamérica y como base de la política de Promoción Popular, constituyéndose en pionera de este enfoque ideológico político en el campo disciplinario del Servicio Social de la Pontificia.

Haciendo un recorrido por cada uno de los cuerpos orgánicos que construyen la teoría de la "participación como integración social," Alicia va instalando en su texto, prolijamente, las claves conceptuales que construían el concepto de "organización social," considerado como el lugar primero de realización de la persona humana hacia la consecución del Bien Común. Esta organización se desarrollaba a través de: a) las organizaciones de base (comunitarias, socioeconómicas, gremiales), como las más pequeñas unidades celulares que organizarían la solidaridad cotidiana y a través de las cuales "la autoridad sacuda la inercia" de 
los sectores populares para que, a través de la educación y capacitación, puedan ser "sus propios agentes de cambio"..., "incorporándose a las tareas del desarrollo."18 b) Estas células básicas debían proyectarse "en cuerpos intermedios que las encaminen hacia la cumbre estatal de la sociedad," definiéndose dichos "cuerpos intermedios" como organizaciones de derecho natural, ubicadas entre el Estado y los individuos, pero respecto de las cuales estaba todo por pensar y por hacer, ya que no había experiencia en América Latina ni era posible seguir orientaciones "ni de las Encíclicas ni de las experiencias europeas; ${ }^{\prime 19}$ c) comunidad territorial sería, por su parte, fruto de la unión de personas que habitan un mismo territorio, unidas por los lazos afectivos que crea la convivencia cotidiana, destinadas a la solución conjunta de los problemas de cada cual, sirviendo de puente entre "la microplanificación local y la macroplanificación nacional," vinculando a los pobladores "de forma más consciente y deliberada a los esfuerzos del Gobierno" (a través de "Juntas de Vecinos, Juntas de Adelanto o Consejo Regional, derramándose hacia los Centros Culturales, Asociaciones de Padres, Centros de Madres, Cooperativas, etc. ${ }^{20}$ "Debe reconocerse que esta iniciativa regional y local no puede surgir fácilmente en forma espontánea, porque la tradición más generalizada en estos países ha sido la anulación de ella y de centralismo absorbente. Pero algunas experiencias de alcance local y regional logradas a lo largo de todo el continente, indican que sólo basta estimularlas para que ellas vuelvan a hacerse presente." ${ }^{21} \mathrm{~d}$ ) Este cuerpo orgánico se completaba a través de la "comunidad funcional" que agrupaba a los individuos según su trabajo. Todos estos organismos habían de articularse de manera dinámica y armónica, sobre la base de un diálogo permanente entre los "organismos representativos de los diversos niveles." 22

Hasta aquí la somera descripción del modelo del andamiaje organizativo sobre el cual se habría de montar la nueva sociedad participativa. Su formulación paradigmática era, al mismo tiempo, un desafío a superar aquello que la negaba u obstaculizaba: la "marginalidad popular" respecto de su "participación en el destino de la sociedad" y concebida como "potencialidad humana actualmente desperdiciada." ${ }^{23}$ Esta integración-participativa estaba llamada a producir un "cambio profundo" en la conciencia de los sectores populares y no podría realizarse a través de 
programas planificados e impuestos "por la burguesía a través de sus técnicos," basados en determinadas opciones religiosas y/o políticas, sino por el propio pueblo, en vista de la solución de sus necesidades comunes, posibilitando los "cambios sociales." Y definía la "participación popular" como "la contribución consciente y organizada del pueblo en los planes y proyectos de desarrollo." ${ }^{24}$ Participación consciente, en función de la cual se jugaba, no sólo el destino de los "sectores marginados," sino el de todo "el resto de la sociedad," ya que no podía "existir una sociedad sana si en ella no participan en forma consciente, todos los sectores que la integran." ${ }^{\prime 25}$ Es decir, la participación popular era la condición de la transformación del sistema social o del Todo.

Sin embargo, esta participación no se produciría espontáneamente; demasiado tiempo, demasiado, había estado el pueblo, dice Alicia, "acostumbrado a una situación marginal frente a las tareas de gobierno." Había, pues, que realizar una ardua labor de convencimiento y de despertar de conciencia para vencer la "natural resistencia que comúnmente se opone a todo proceso de cambio." El objetivo ideal era poder llegar a sentar en una misma mesa de diálogo -tal como lo recomendaba el Seminario Regional Latinoamericano-a los planificadores y a los representantes de la colectividad, con el fin de que éstos fuesen progresivamente compartiendo "las responsabilidades de gobierno y solidarizándose conscientemente con las decisiones que toman los técnicos con base a la iniciativa popular." ${ }^{26}$ Desde esta perspectiva, el punto final de la participación política de la comunidad era una mesa de diálogo con los técnicos, que portaban las claves del "desarrollo"; se suponía que el diálogo en torno a los desafíos y tareas del desarrollo era la base para el éxito de dichas políticas. En este sentido, la participación de las bases culminando en la mesa de los técnicos, revela que la visión de dicha participación popular es funcional al proyecto de desarrollo económico social, con lo cual se identifica lo político. Lo "político" queda definido, así, como un diálogo en torno a decisiones técnicas que necesitan del aval y el apoyo de la comunidad para operar con éxito. Aquí entraba, a juicio de Alicia, a jugar un importante rol el Servicio Social (S.S.).

No habría diálogo entre pueblo y técnicos si es que no existían canales de comunicación entre ambos, vasos comunicantes. 
Los partidos políticos, modernos mediadores entre pueblo e instituciones políticas, estaban concentrados, a los ojos de Alicia, en sus "disputas tradicionales." ¿Quién mejor que ellas, las Asistentes Sociales, podían hacer este trabajo de comunicación política, sustituyendo en buena lid a los partidos? Sí, quién mejor que ellas, que trabajaban directamente con el pueblo, conociendo mejor que nadie "el drama humano del ser que sufre porque no es tomado en cuenta; ellas saben que el asumir responsabilidades por sus actos es lo único que permite a las personas valorizarse ante sí mismas; que no basta el otorgar beneficios, el 'dar cosas'; que lo más importante es defender y hacer consciente en cada ser humano su dignidad de tal." ${ }^{27}$ Aunque el "respeto por la persona" en el sentido de su "derecho a la libertad y responsabilidad" formaba parte, dice Alicia, de los principios fundamentales del Servicio Social, ella tiene dudas respecto de la aplicación de dichos principios en su práctica profesional. “¿En qué medida ha contribuido la asistente social con su labor -se pregunta- a que se efectúen cambios estructurales que permitan esta participación social? ¿Somos un grupo de presión que motiva el cambio y crea conciencia de lo urgente que es llevarlo a efecto?"28

Esta gran duda política respecto de la práctica social de su saber es la que ha motivado a Alicia a salir en busca de 50 de sus compañeras y colegas para indagar acerca de su trabajo y acerca de la percepción que ellas tienen del mismo, en esos cruciales momentos de cambio histórico político en Chile. Así, descubrió que un $64 \%$ de ellas no estaba de acuerdo "con la orientación y acción que desarrolla el Servicio Social en el país. Esto significa una falla profunda -diagnostica Alicia- que está desvirtuando la eficacia de una profesión de tanta importancia y trascendencia social como es la nuestra." ¿Cuáles eran las razones de este descontento? Principalmente dos: en primer lugar, una percepción de que la intervención que realizaban era ineficaz, sintiéndose impotentes para entregar una solución "integral" a los problemas sociales con que se enfrentaban diariamente y, en segundo lugar, cuestionaban la "poca participación del Servicio Social en los planes y programas del gobierno." ${ }^{29}$ Es decir, el descontento profesional estaba hablando claramente de política, es decir, del deseo de ser "sujetos políticos:" de constituirse en un cuerpo orgánico que fuese capaz de cuestionar su saber y su práctica, así 
como de actuar en el gobierno de la sociedad. Se estaba incubando el malestar propio de los prolegómenos de un cambio.

Ha llegado, a nuestro parecer, el momento de detenerse y evaluar sinceramente el trabajo realizado, no con el fin de desvalorizarlo y desconocer la labor efectuada en numerosos años de profesión, sino que, al analizar sin ideas preconcebidas la evolución de nuestra sociedad, ver si es necesario cambiar un poco o totalmente la orientación del trabajo, considerando los nuevos elementos de juicio y las nuevas circunstancias surgidas a través del tiempo, como consecuencia de dicha evolución. ${ }^{30}$

Con aguda intuición e inteligencia, aunque tímidamente, Alicia está revelando el deseo del cambio, que siempre se inicia con el punto de detención de la inercia histórica; punto de detención que, cuando se halla preñado de mirada crítica y de nuevas ideas $\mathrm{y}$ aspiraciones, como las de Alicia, es siempre punto de partida:

Sostenemos que la Asistente Social debe estar en medio de la problemática del desarrollo. Este énfasis en lo social no significa un desprecio por el trabajo asistencial, pues estamos conscientes de que existen circunstancias que lo hacen indispensable y urgente (...), pero pensamos que su labor primordial es promover un cuerpo orgánico social, sano y bien estructurado, que haga posible una democracia de participación, dentro de la cual cada persona se sienta auténticamente comprometida. $^{31}$

Su proyecto S.S. instalado en el centro del punto de detención que Alicia propicia, es un nuevo proyecto político llamado a transformar la Asistente Social, junto con sus asistidos, en sujetos históricos vistos como cuerpos organizados y participativos, ejerciendo la democracia, considerada como la acción de "sembrar calor humano y vivificante en una sociedad dominada por el egoísmo, la competencia y la rebelión;" ${ }^{22}$ todo esto, en el marco del proyecto de "desarrollo," que vinculaba el progreso social con la valorización del "ser" (más que del "tener"). La materia prima para cambiar la dirección del S.S. existía: los principios y la dinámica del S.S. se basaban en la idea de grupo, "cuyo núcleo inicial es la familia, extendiéndose luego hacia otros conjuntos mayores." No era, pues, a su juicio, necesario hacer una cirugía 
mayor en los fundamentos de la formación profesional; aún más, el objetivo seguiría siendo el mismo, tal como lo había definido para el Servicio Social las Naciones Unidas en 1959: "contribuir a una adaptación mutua entre los individuos y su medio social."

Pensamos - plantea Alicia- que el Servicio Social no necesita cambiar la Filosofía que le es propia, ni buscar nuevos fundamentos que justifiquen su labor, sino más bien encontrar una nueva fórmula de expresión, que le permita en forma más eficaz y en mayor consonancia con las circunstancias actuales, responder a los requerimientos y necesidades de la hora presente. ${ }^{33}$

Si los principios de la profesión se lo permitían, ¿por qué no iniciar el cambio en el territorio de la práctica social? Alicia finaliza su reflexión crítica no ofreciéndole a sus colegas, como antes, la "Guía de las Instituciones de Beneficencia," sino una completa información acerca de las organizaciones sociales con las que podrían contar para iniciar el vuelco hacia un servicio social participativo y comunitario, principalmente: Cooperativas, Sindicatos, Juntas de Vecinos y Centros de Madres; las cuatro patas de una mesa para el diálogo civil y la acción participativa desde la base: familiar, barrial y laboral.

Y concluye que es de vital importancia realizar un profundo estudio de nuestra realidad social y, de acuerdo a él, orientar la labor y acción del Servicio Social. Pensamos que nuestra profesión cuenta con valiosos recursos para contribuir a la solución de los problemas sociales que se afrontan en la hora presente, por lo que le cabe una gran responsabilidad frente a ellos, debiendo, por consiguiente, aportar todos los medios a su alcance para lograr superarlos. ${ }^{34}$

Alicia ha osado ponerse, junto a sus hermanas de profesión, ante el espejo, para mirarse y reconocer el valor y la belleza de su trabajo, invitándolas a atravesar dicho espejo y, como la Alicia del cuento, encontrarse con el verdadero país que las esperaba para realizar conjuntamente la utopía de su historia. El espejo de Alicia le respondía que su mirada andaba por buen camino y que a sus propias espaldas se veía venir lo que su intuición alumbraba. No pasó mucho tiempo: como es sabido, en 1967 se revolucionó 
la P. Universidad Católica, exigiendo sus estudiantes una total reforma curricular y un explícito compromiso de la universidad con el pueblo y el cambio social. Simultáneamente, en octubre de ese año se realizó el "Primer Congreso Nacional de Escuelas de Servicio Social," cuya conclusión primera del "Grupo Teoría" planteó que "las escuelas de Servicio Social deben formar un profesional que sea agente de cambio dirigido hacia el desarrollo económico-social de los países subdesarrollados." ${ }^{\prime 35}$ La crítica, con claros atisbos de revuelta, ocurrió en 1968 en la Universidad de Chile y el resto de las universidades del país. Los saberes disciplinarios debían ponerse al servicio y en sintonía con los procesos políticos y sociales emancipadores y de cambio estructural que, durante toda esa década, vivía el Tercer Mundo en general y América Latina y Chile en particular. Como dijimos, en sucesivos congresos latinoamericanos que habían tenido lugar en esta década del sesenta -en Costa Rica, Perú, Porto Alegre, Caracas-, se había estado hablando de la urgente necesidad de reformular la orientación y el sentido de la profesión, con el objetivo de romper con su paradigma formativo y práctico, al que se calificó de tradicionalista y puesto al servicio del status quo.

La "reorientación" del servicio social al finalizar la década de 1960 en Chile, decía relación con una profunda resignificación de la disciplina, en la que ésta, rompiendo su "autosuficiencia" o su "tecnicismo," echara raíces en el suelo de la historia social chilena y latinoamericana. Este suelo fértil, nutrido de los dolores del subdesarrollo, pugnaba por fructificar con nuevas fuerzas vitales que emergían desde el seno del pueblo. De este campo de experiencias históricas y de proyectos de cambios debía nutrirse y regenerarse el saber y la práctica del servicio social, nadando en el mismo sentido de la corriente de sus aguas, abandonando el sentido inverso, ya casi imposible, por lo demás, de remontarse. ${ }^{36}$

No es nuestra intención aquí hacer la historia de este movimiento ${ }^{37}$ sino comprender que la nueva orientación doctrinaria, política y práctica del Trabajo Social de ese momento, condujo a una progresiva transformación de la propia institucionalidad disciplinaria y del campo de su saber hacia una politización del mismo, poniéndose en sintonía explícita con la problemática y los proyectos políticos que se estaban desarrollando entonces en 
el proceso social chileno; específicamente, esto lo lleva a comprometerse con la "participación social y popular" que se estaba desarrollando como tendencia y deseo de la sociedad de la época y que se propiciaba en Chile como política social oficial y como búsqueda y texto de Alicia desde el año 1964.

\section{La participación como concientización. María Angélica y Ana María tras la emancipación de las mujeres campesinas}

Al finalizar la década del sesenta, las egresadas de Asistentes Sociales de la P. Universidad Católica, M. Angélica Giroz y Ana María López, se preocuparon de la "ausencia de inquietudes y estudios" relativos a la participación de las mujeres campesinas chilenas, así como del escaso compromiso de las Asistentes Sociales chilenas "en el proceso de cambio del sector campesino." Esto, a pesar de que Chile vivía un revolucionario proceso de reforma agraria y de sindicalización campesina, llamado a reestructurar el orden imperante.

A partir de esta preocupación y diagnóstico y haciéndose eco de la concepción de ese entonces de la participación como "derecho" social humano, juzgaron que "la mujer campesina no ha participado de la vida social y económica del país." Haciéndose cargo de la visión política que entonces se tenía de la mujer chilena como "barrera a los cambios sociales," ellas ven la necesidad de producir un corte al respecto, ya que "tanto el hombre como la mujer tienen el derecho y el deber de participar en la estructuración del sistema social de la nueva sociedad." Atribuyen la renuencia al cambio de las mujeres a su tradicional sometimiento al hombre, "marginándola de diversos campos de acción."

Decidieron, así, indagar la situación de la participación femenina en los sindicatos "Manuel Rodríguez" y "Despertar Campesino," así como en las cooperativas "El Chamanto," "Patria Nueva" y "Valle del Putaendo," intentando, a través de sus saberes y de su práctica, contribuir a su participación en dichas organizaciones campesinas. Conscientes de la hora histórica que vivía el país, especialmente en el ámbito campesino y agrario, 
y del papel que a los/as asistentes sociales les tocaba jugar en esos decisivos momentos de transformación social, M. Angélica y Ana María consideraban que "el asistente o trabajador social tiene el deber de estar presente y comprometido en la integración y cambio de la comunidad campesina, actuando como promotor de este proceso. ${ }^{\prime 38}$

Inspiradas en el concepto de "integración," éste ya a fines de los sesenta ha asumido la crítica de su posible estática adaptativa y ha ido adoptando ahora, en los nuevos escritos de un Mattelart -junto a Manuel Antonio Garretón- de fines de los agitados sesenta, una perspectiva claramente dinámica, definiéndose dicha "integración" como "participación," a la que expresamente adscriben M. Angélica y Ana María. Y si bien se sigue haciendo la distinción entre participación pasiva (receptiva) y activa (toma de decisiones), ahora, en un lenguaje propio de la pedagogía liberadora de Paulo Freire, se define la "participación como el grado de conciencia que ha alcanzado un individuo o colectividad sobre su realidad, mediante el cual se compromete, decide y actúa en los diferentes niveles, con iniciativa propia." En definitiva, la "integración participativa consciente' en los consabidos 'cuerpos intermedios' apuntaría a "un dinamismo tal, que tienda a producir un cambio y desarrollo en la sociedad total." La participación tendría que articular la participación pasiva y activa en vista del "poder social." Desde esta perspectiva del "poder," ellas entienden que la sociedad chilena es una sociedad "desintegrada," en el sentido de que "grupos minoritarios" estarían concentrando el poder político, cultural, económico y social del país," problema que habría que revertir. Hacia esto apuntan en su interés por la participación campesina, concibiendo la "integración sindical y cooperativa" como "una forma de organización de los campesinos para llegar a una toma del poder, junto con las masas urbanas organizadas y estructurar el país de modo que sean los grupos mayoritarios quienes tengan el poder. Sólo una vez que el pueblo organizado logre tomarse el poder social realmente, se llegará a una verdadera integración." El objetivo final de la integración social era crear una "nueva sociedad," modificando "de arriba a abajo la estratificación social."39

Vemos, así, cómo el concepto de integración ha llegado a ser, hacia finales de la década del sesenta, una forma de concebir la 
"toma del poder": un concepto que estas Alicias repiten a lo largo del texto y que ya prepara las percepciones, deseos e imperativos políticos de la transición a los años 70. Como expresión de esta transición ideológica del concepto de "integración," ellas se hacen cargo, a partir de los nuevos planteamientos de Armand junto a Michelle Mattelart, de la crítica que ya entonces se había hecho a dicho término:

El gran escollo de cierta visión de la integración es el pretender que consiste solamente en hacer participar los grupos 'marginales' a una sociedad ya constituida, sin considerar su transformación radical. Pero en ningún caso se trata de edificar sobre antiguos cimientos con elementos arquitectónicos nuevos, lo que se persigue es crear una sociedad nueva. Resulta absurdo hablar de un hombre nuevo si no se admite la necesidad de una transformación radical y total de la sociedad. Una concepción parcial de la integración que actúa únicamente con las clases inferiores (...) permite que subsista en la sociedad un (...) marco de referencia clasista, puesto que no se propone un ideal común que presida la elaboración de la nueva sociedad. (...) Una ideología liberal de integración que esté actuando en una sociedad en proceso de cambio, interviene como instrumento de concientización. ${ }^{40}$

Se puede apreciar, a través del textos de las Alicias, cómo los Mattelart, abiertos desde un principio a un concepto dinámico de "integración," han hecho transitar este concepto central de la Promoción Popular hacia la izquierda y hacia la Pedagogía de la Liberación, es decir, hacia la cuestión de la participación entendida como "toma de conciencia" que, al actuar en una sociedad en cambio, terminaría por expresarse como "toma del poder" y como transformación estructural de las relaciones de clase en la sociedad. Transición ideológico-teórica o encuentro histórico entre la sociología europea y la teoría pedagógica latinoamericana que está alcanzando a los saberes y prácticas del servicio social en el Chile de los albores del 70. De este modo, podemos apreciar cómo se ha ido transformando, sutilmente, el lenguaje de la "teoría de la participación," desde un lenguaje "promocional" y muy próximo al proyecto D.C., a un lenguaje pro revolucionario, lo que está mostrando un proceso de intensa transición ideológica. 
En este marco, la temática de la participación y emancipación de las mujeres, en todos los niveles sociales, se comprendía, en la perspectiva de los Mattelart y de las Trabajadoras Sociales María Angélica y Ana María, como la incorporación de una nueva fuerza de presión y compromiso con el "proceso revolucionario" en vista de la construcción de la nueva sociedad, realizando un doble proceso emancipador, tanto respecto de sus relaciones tradicionales con el hombre y su rol en la familia, como respecto del cambio social en general. ${ }^{41}$ Doble salto cualitativo que, sin duda, significaba un fuerte desafío para las mujeres chilenas que vivían la alta tensión del cambio histórico de aquella época.

En el caso específico de las mujeres campesinas, se debía tender al desarrollo de su "conciencia participativa." En la práctica, haciéndose eco de la política de INDAP, M. Angélica y Ana María consideraban que aquellas no debían constituir "organizaciones femeninas" separadas, sino integrarse a las organizaciones de cooperativas y sindicatos campesinos, considerados habitualmente como territorio masculino, transformándose en un campo integrado de interés comunitario y de superación tanto del individualismo como de la familia como núcleo cerrado. Más que meras organizaciones, estos organismos estaban llamados a desarrollar un "método cooperativo," promoviendo la "participación democrática" en el proceso productivo agrario y nacional. ${ }^{42}$

Con el fin de evaluar el trabajo de capacitación de INDAP en el sentido de la integración participativa de las mujeres campesinas a las organizaciones cooperativas y sindicales, así como con el objetivo de "conocer si los sindicatos y cooperativas campesinas promueven la participación de la mujer campesina," María Angélica y Ana María partieron al campo en busca de aquellas mujeres y organizaciones, con el fin de efectuar su indagación en el terreno concreto de la vida histórica que entonces vivía el área reformada.

Premunidas de su concepto de "participación" en los términos propios de la pedagogía de Paulo Freire, definida como "el grado de conciencia que ha alcanzado un individuo o una colectividad sobre su realidad, mediante el cual se compromete, decide y actúa con iniciativa propia" ${ }^{\prime 43}$ y luego de su extenso e intenso 
trabajo de campo, donde entrevistaron en decenas de mujeres y hombres campesinos, observando y viviendo junto a su vida y quehacer, Ana María y M. Angélica concluyeron, en general: a) que si bien la incorporación de las mujeres campesinas a los sindicatos era menor que en las cooperativas, su "participación" era más notoria, desarrollando incluso algunas gran capacidad de liderazgo, lo cual se explicaba por su condición de "trabajadoras asalariadas"; organizaciones a las que, por ley, estaban impedidas de ingresar mujeres no asalariadas y b) que la participación de las mujeres campesinas en las cooperativas era más bien pasiva, actuando como expectantes de beneficios y meras votantes de líderes masculinos carismáticos, lo que las Trabajadoras Sociales relacionan con el hecho de que mantenían su rol principal como dueña de casa-cooperada con permiso del marido y con el exclusivo fin de proporcionar algún beneficio económico familiar, sin integrarse activamente ellas en algún proyecto productivo al interior de la cooperativa. Las Alicias responsabilizan de esta pasividad productiva de las mujeres cooperadas principalmente a INDAP por "falta de asistencia técnica y crediticia" y, en general, por "ausencia de ayuda real y efectiva frente a estos proyectos (productivos), lo que estaría frustrando las expectativas campesinas," concentrándose la capacitación pro liderazgo en los hombres campesinos sindicados y cooperados, "dejando a las mujeres en los Centros de Madres." 44

Fuerte crítica, sin duda, a la inconsecuencia de un organismo de gobierno respecto del estímulo a la participación de las mujeres campesinas en los "cuerpos intermedios" del área reformada del campo chileno, poniéndose, así, en juego "la formación de un espíritu comunitario tanto en el hombre como en la mujer, uno de los objetivos que se persigue a través del proceso de Reforma Agraria." Según las Asistentes Sociales que acudieron a saber y a dialogar sobre la vida y nivel participativo de la mujer campesina en el Chile de ese entonces, "el hecho de que la mujer participe en organizaciones paralelas como Centros de Madres, ha dificultado su integración a las organizaciones de base, dado que su participación en aquellas tiene poca injerencia en el proceso socioeconómico del sector campesino." ${ }^{45}$ Ana María y María Angélica proponen que INDAP conforme equipos interdisciplinarios mixtos para concienciar y capacitar a las mujeres 
campesinas en proyectos productivos, especialmente talleres, vía a través de la cual ellas opinan que las campesinas podrían romper su aislamiento y entrar comunitariamente a participar y crear e incluso liderar su medio social.

Es decir, Ana María y M. Angélica han llegado a tocar el corazón de un hecho decisivo de la historia política social de las mujeres y de la democracia de Chile de los sesenta: la participación, en términos de "toma de conciencia y empoderamiento" de las mujeres y, en especial, de las mujeres campesinas, no dependía sólo de su integración a los "cuerpos intermedios" existentes, sino básicamente, de su incorporación al "proceso productivo;" era la modalidad comunitaria que adquiriese esta incorporación productiva de la mujer lo que le permitiría elaborar una mentalidad social comunitaria y participar en la construcción de una nueva mujer y una nueva sociedad.

A partir de su experiencia, su intención es también influir sobre el currículo formativo de su profesión, recomendando a la Escuela de Trabajo Social P.U.C. "agregar al currículo académico estudios sobre realidad campesina," promoviendo, al mismo tiempo, la participación de las trabajadoras sociales en la organización del campesinado, asumiendo tareas de educación, capacitación y concientización. "La concientización debería proporcionar elementos para la ubicación de las personas en el momento histórico que se vive, problematizando la realidad en la cual están sumergidos y promoviendo a que participen como sujetos activos dentro del proceso de desarrollo," dicen. ${ }^{46}$ Armand y Michelle Mattelart y Paulo Freire estaban estrechando manos en la praxis de las Trabajadoras Sociales chilenas de fines de los sesenta.

El fruto colectivo en el que estos pequeños-tremendos esfuerzos solitarios se inscriben no se hizo esperar. La escuela de Trabajo Social P.U.C. transformó su currículo en el sentido de la intervención participativa y, simultáneamente, en 1970 dicha escuela funda la revista Trabajo Social, órgano de expresión de la Escuela de Trabajo Social P.U.C., llamada a sustituir la fallecida revista Servicio Social, a recoger el ideario de la "reformulación" del trabajo social latinoamericano y chileno y a tomar las riendas de la vanguardia concientizadora del saber y la praxis del Trabajo 
Social en vista del compromiso por el cambio social en Chile y América Latina.

"Creemos que la reconceptualización es imprescindible, pero debe cumplir algunos requisitos para que realmente responda a América Latina y sus necesidades de cambio. Entre ellos, énfasis en formación científica que permita interpretar correctamente la realidad; análisis profundo de la realidad nacional y latinoamericana; trabajo directo en terreno para vivenciar y compartir la problemática de los trabajadores desde adentro, comprenderla críticamente y sistematizarla.

La revista nace de estas inquietudes, las que sabemos son semejantes a las de muchas otras escuelas en América Latina y de otros trabajadores sociales; por lo tanto, la invitación a participar es innecesaria, ya que la participación común es esencial tanto para la revista como para la acción de todos. ${ }^{47}$

La Alicia primera había comenzado recogiendo, piedra a piedra, las primeras formulaciones de la teoría participativa, auscultando el malestar de muchas e induciéndolas a dar un giro hacia un trabajo social organizativo de cuerpos sociales populares vivos, como parte de un todo cuerpo nación que se nutría desde las decisiones de las bases. Las Alicias segundas, M. Angélica y Ana María, han acudido al campo, en busca de las mujeres campesinas chilenas-latinoamericanas a inducir su organización y participación activa, consciente, como expresión de su ejercicio de poder. Ellas han realizado, así, por sí mismas, las principales inquietudes y tareas futuras que demanda la reconceptualización latinoamericana del Trabajo Social y que recoge expresamente la revista Trabajo Social de la escuela P.U.C. Las Alicias distaban mucho de estar solas. Desde los pies andantes de su pequeña historia crecían ramas de una historia mayor.

\section{A modo de conclusión}

La investigación realizada ha intentado seguir la génesis y evolución del concepto de "participación" en los años sesenta, 
puesta en las manos y tal como es recogida por el discurso y la práctica de las asistentes sociales bajo la inspiración de las fuentes teóricas -teológicas, sociológicas, políticas y pedagógicas- que circularon en Chile y América Latina en los sesenta. Esta opción metodológica para estudiar la teoría, que podríamos identificar como "opción por el modo de apropiación social de la teoría," nos permite visualizar el impacto que ésta tiene en la formación y el quehacer de personas y actores concretos de la sociedad y, especialmente, su modo de apropiación en Latinoamérica (¿copia, asimilación, reelaboración?), tal como lo vimos en la primera Alicia; como también la creación de teorías propias de América Latina y el debate y posibilidades de síntesis de ambas vertientes teóricas; síntesis que se encarna en las segundas Alicias de la historia.

$\mathrm{Al}$ respecto, hemos podido percibir dos versiones de dicho concepto de participación: a) la versión sociológica europea católica aportada por Roger Vekemanns, especialmente a través de su discípulo, un "primer Armand Mattelart," que buscaba aportar los conceptos que inspiraran la construcción de un modelo de sociedad, una suerte de "utopos," 48 , basado en un organigrama corporal constituido por un eje dado por una base familiar y una cabeza estatal, interconectada entre sí a través de "cuerpos intermedios" en el seno de los cuales se realizaría el proceso de integración, y armonización de la sociedad civil y de la estructura social en su conjunto; una participación como "integración" como "formar parte" y "tomar parte" en los procesos sociales, políticos y productivos de la sociedad que resultaría en un proceso de "socialización," "comunidad" y "democracia participativa." b) La versión de la pedagogía de la liberación del brasilero Paulo Freire, que concibe la "participación" y la "integración" como un proceso dialéctico a través del cual el pueblo oprimido va despertando a la percepción de la realidad de su mundo de opresión y tomando progresivamente conciencia de su sujeto como actor y creador de su historia, incorporándose o integrándose críticamente a su propia historicidad, con el apoyo de la "educación popular:" proceso que denomina "concienciación."

El derrotero seguido por nuestro trabajo nos muestra que estas dos versiones del concepto de integración experimentan, 
tanto a nivel de la teoría sociológico política, como a través de su influjo en ciertos saberes y prácticas disciplinarias, especialmente en el Trabajo Social (objeto de nuestra indagación), un proceso de interesante fusión, inspiradas por la evolución que experimenta la teoría mattelartiana de la última fase de la década del sesenta, junto a la publicación en Chile del texto de Freire, La educación como práctica de la libertad, en 1967. Esta fusión se expresa en una voluntad política por inducir un proceso de participación social y popular en la sociedad chilena que, desde su organización y empoderación en los "cuerpos intermedios," la sociedad y especialmente el pueblo, fuese "tomando conciencia y poder" en la sociedad en proceso de transformación, constituyéndose en actores y sujetos históricos de dicho proceso; fenómeno que conduciría a un cambio de la estructura de las relaciones de clases de la sociedad, en vista de una democratización social ampliada y de la construcción de una "nueva sociedad": una "sociedad abierta" o una "sociedad comunitaria."

Quiero agradecer a estas Alicias el tremendo esfuerzo desplegado en sus personales proyectos, en pos de la construcción de ese país de las maravillas, participativo, que en este, su futuro o nuestra actualidad, aún añoramos.

\section{Notas}

1 Este artículo forma parte del proyecto Fondecyt $N^{\circ} 1050304$.

2 La autora de este artículo es académica titular del Instituto de Ciencias Sociales de la Universidad Austral de Chile. Se agradece la colaboración en esta investigación de Claudio Aguayo y la colaboración especial para esta parte de la investigación de Julieta Gho.

3 Ver, por ejemplo, el artículo de Sara Larraín en La Nación del jueves 1 de noviembre, 2007, reclamando de la ausencia de los movimientos ambientalistas en una mesa sobre legislación de impacto ambiental a la cual se convocó solamente al empresariado industrial y comercial.

4 Ver La Nación, Reportajes, 5 de agosto, 2007.

5 El problema de la participación es un tema de debate reiterado en las universidades chilenas actualmente, especialmente entre los estudiantes de historia, quienes, al "portar la memoria de la participación social en Chile" (Luis Berger, Presidente del Centro de 
Alumnos de la Escuela de Pedagogía en Historia y Ciencias Sociales de la U. Austral de Chile) se sienten con mayor responsabilidad en este sentido.

6 Diego Palma, "La participación y la construcción de ciudadanía," Documento de Trabajo $\mathrm{N}^{\circ}$ 27, Centro de Investigaciones Sociales, Universidad ARCIS, Santiago, s/f, p. 5.

7 Ver Theodor Adorno. La ideología como lenguaje. Madrid: Taurus, 1982, p. 37.

8 Ver al respecto Hayden White. Metahistoria. La imaginación histórica en la Europa del siglo XIX. Buenos Aires: F.C.E., 1998.

9 Ver Michel Foucault. "Curso del 14 de enero de 1976." En Microfísica del poder, Buenos Aires: Ediciones La Piqueta, 1992.

10 Sin poder referirnos en este texto, por motivos de espacio, a las doctrinas que formulan en la década del sesenta en América Latina lo que identificamos como "la ideología participativa," remitimos a los lectores al pensamiento de Roger Vekemanns y Armand Mattelart, como representantes de la escuela sociológica católica europea y fundadores de la Escuela de Sociología de la P.U.C., y a los textos de Paulo Freire, como creador de la Pedagogía de la Liberación, una teoría de emancipación participativa del pueblo latinoamericano desde una perspectiva cristiana, quien también participó del proceso de cambios que vivió Chile en los sesenta.

11 Congreso Panamericano de San José de Costa Rica (1961), Congreso Panamericano de Lima (1965), Primer Congreso Latinoamericano de Servicio Social de Porto Alegre (1965), Congreso Panamericano de Servicio Social de Caracas (1967). Ver M. Eugenia Parra, Paulina Muñoz, Betsabe Padin, Manuel Cabrera y Victoria Gallardo, El asistente social como agente de clase. Tesis para optar al título de Asistente Social, Universidad de Chile, Santiago, 1971, pp. 128-130.

12 Ver M.A.Illanes. Cuerpo y sangre de la política. La construcción histórica de las Visitadoras Sociales. Chile, 1880-1940, LOM, Santiago, 2007.

13 Alicia Montes Sotomayor. "Algunos aspectos de la realidad actual en relación al Servicio Social." Memoria para optar al título de Asistente Social de la Escuela de Servicio Social 'Elvira Matte de Cruchaga' de la P. Universidad Católica de Chile, 1964, p. 6.

14 Ibid., pp. 6-7.

15 Roger Vekemanns. Conferencia "Sociedad democrática," dictada en el Instituto Humanístico en 1963 y citada en Alicia Montes, op. cit., p. 8.

16 Alicia Montes, ibid., p. 8. Corresponden a sus anotaciones de lo expuesto por Carlos Domínguez acerca de las funciones de subsidiariedad del Estado, en las Jornadas Sociales de Osorno realizadas en 1964.

17 Informe a la memoria de Alicia Montes S. de Jorge Precht Pizarro, profesor de Doctrina Social de la Iglesia de la Escuela de Servicio 
Social 'Elvira Matte de Cruchaga' de la P. Universidad Católica de Chile, fechado el 11 de diciembre de 1964. Documento inserto al final de dicha Memoria.

18 Alicia Montes, ibid., p. 13. Cita de Ramón Venegas y Amalio Fiallo. "Principales requisitos para la integración popular del desarrollo." En Semana Sociales. Santiago: Chile, 1963, p. 8.

19 Ibid., pp. 15-16.

20 Alicia Montes, ibid., p. 17, citando a Alfredo Matte, "Integración funcional y territorial." En Semanas Sociales, Santiago, 1963, p. 5.

21 Alicia Montes, ibid., pp. 17-18, citando al "Seminario Regional Latinoamericano sobre el papel del Desarrollo de la Comunidad en la Aceleración del Desarrollo Económico y Social," CEPAL, 1964, p. 16.

22 Ibid., p. 19

23 Ibid., p. 23

24 Ibid., p. 22

25 Ibid., p. 21

26 Ibid., pp.23-24. Alicia está siguiendo las indicaciones y va citando al Seminario Regional Latinoamericano, sobre el papel del desarrollo de la comunidad en la aceleración del desarrollo económico-social, CEPAL, 1964 , p. 16.

27 Ibid., p. 27

28 Ibid., p. 28

29 Ibid., p. 29

30 Ibid, p. 31

31 Ibid, p. 30-31

32 Ibid., p. 31

33 Ibid., p. 33

34 Ibid., p. 97

35 Este "Primer Congreso Nacional de Escuelas de Servicio Social" fue convocado en 1966 por la Asociación Chilena de Escuelas de Servicio Social. Se mandó primero un cuestionario a solicitud de la Asociación Latinoamericana de Escuelas de Servicio Social, relacionado con el tema de la formación profesional de dichas escuelas a la luz del momento histórico latinoamericano. No todas las escuelas del país respondieron al llamado; no obstante, el documento contiene un análisis bastante completo de la formación en las escuelas de S.S. chilenas. Ver "Primer Congreso Nacional de Escuelas de Servicio Social," Santiago, 1-4 de octubre, 1967, documento del Instituto de Servicio Social de la Facultad de Cs. Jurídicas y Sociales de la Universidad de Chile.

36 Ver M. Angélica Illanes, "Las Prometeas. Saberes y prácticas de las visitadoras y trabajadoras sociales chilenas en el siglo XX," en Sonia Montecinos (editora), Mujeres chilenas. Fragmentos de una historia, Editorial Cuarto propio, Santiago, 2008. 
37 Para una referencia histórica a este movimiento de reformulación en Chile ver ibid.

38 M. Angélica Giroz y Ana María López, “Evaluación del proceso de integración de la mujer campesina en las organizaciones de base: cooperativas y sindicatos," Tesis de Grado para optar al Título de Asistente Social, P. Universidad Católica de Chile, Santiago, 1969, p. I y 1. Para lograr su objetivo, las autoras se relacionaron con INDAP (Instituto de Desarrollo Agropecuario) a través de la socióloga de INDAP y profesora de la Escuela de Sociología de la PUC, María Raquel Ugarte.

39 Ibid., pp. 1-7. Las autoras citan a A. Mattelart y M. A. Garretón, "Integración nacional y marginalidad."

40 Armand y Michelle Mattelart, "La mujer chilena en la nueva sociedad," citados en Ibid, p. 7-8.

41 Ibid., p. 9

42 Ibid., pp. 10-12

43 Ibid., p. 105

44 Ibid., p. 112-116

45 Ibid., p. 118

46 Ibid., p. 124

47 Trabajo Social, Año I, julio-agosto-septiembre, 1970, Editorial, p. 4.

48 Con el término "utopo," basándome en la terminología de Tomás Moro en su Utopía, quiero referirme a un "modelo" racional y planificado de sociedad justa, equitativa y armoniosa y lo diferencia de "utopía" que, con el desarrollo del lenguaje tiene la connotación actual de un "proyecto" o de un ideario de sociedad, lo que necesariamente acompaña a cualquier programa social-político.

\section{Bibliografía}

Adorno, Theodor. La ideología como lenguaje, Madrid: Taurus, 1982.

CEPAL. "Seminario Regional Latinoamericano sobre el papel del Desarrollo de la Comunidad en la Aceleración del Desarrollo Económico y Social," Santiago: 1964.

Foucault, Michel. "Curso del 14 de enero de 1976." En Microfísica del poder, Buenos Aires: Ediciones La Piqueta, 1992.

Giroz, M. Angélica y Ana María López. "Evaluación del proceso de integración de la mujer campesina en las organizaciones de base: cooperativas y sindicatos," Tesis de Grado para optar al Título de Asistente Social, P. Universidad Católica de Chile, Santiago, 1969.

Illanes, M. Angélica. Cuerpo y sangre de la politica. La construcción histórica de las Visitadoras Sociales. Chile, 1880-1940, Santiago: LOM, 2007. 
------ "Las Prometeas. Saberes y prácticas de las visitadoras y trabajadoras sociales chilenas en el siglo XX." Ed. Sonia Montecinos, Mujeres chilenas. Fragmentos de una historia. Santiago: Editorial Cuarto propio, 2008.

Matte, Alfredo. "Integración funcional y territorial." En Semanas Sociales, Santiago: 1963.

Mattelart, Armand y Manuel Antonio Garretón. Integración nacional y marginalidad, Santiago.

Mattelart, Armand y Michelle, La mujer chilena en la nueva sociedad, Santiago.

Montes, Alicia. "Algunos aspectos de la realidad actual en relación al Servicio Social," Memoria para optar al título de Asistente Social de la Escuela de Servicio Social 'Elvira Matte de Cruchaga' de la P. Universidad Católica de Chile, 1964.

Palma, Diego. "La participación y la construcción de ciudadanía." Documento de Trabajo $\mathrm{N}^{\circ} 27$, Centro de Investigaciones Sociales, Universidad ARCIS, Santiago: s/f.

Parra, M. Eugenia, Paulina Muñoz, Betsabé Padin, Manuel Cabrera y Victoria Gallardo. El asistente social como agente de clase. Tesis para optar al título de Asistente Social, Universidad de Chile, Santiago, 1971.

Venegas, Ramón y Amalio Fiallo, "Principales requisitos para la integración popular del desarrollo." En Semana Sociales, Santiago, Chile, 1963.

White, Hayden. Metahistoria. La imaginación histórica en la Europa del siglo XIX. Buenos Aires: FCE, 1998. 